\title{
The effectiveness of soursop seed (Annona muricata L.) agains Callosobruchus maculatus F. (Coleoptera: Bruchidae)
}

\author{
Rama Ginanjar Gilang ${ }^{1}$, Nenet Susniahti², Danar Dono ${ }^{2} *$ \\ ${ }^{1}$ Graduate of Department of Plant Pests and Diseases, Agriculture Faculty, Universitas Padjadjaran, Jatinangor, West Java, \\ Indonesia, 45363 \\ ${ }^{2}$ Department of Plant Pests and Diseases, Agriculture Faculty, Universitas Padjadjaran, Jatinangor, West Java, Indonesia,
} 45363

*Corresponding Author: danar.dono@unpad.ac.id

\begin{abstract}
Callosobruchus maculatus F. (Coleoptera: Bruchidae) is one of the main pests that cause damage to mung beans in storage. This research was conducted to determine the effective dose of soursop seed powder (Annona muricata) resulting mortality and reduced emerging of adult of $C$. Maculatus first-generation. This research was conducted at Plant Pest Laboratory, Department of Plant Pests and diseases, Faculty of Agriculture, Universitas Padjadjaran, Jatinangor using Complete Randomized Design (CRD) with 6 treatments and 5 replications. The treatments were five doses of $A$. muricata seed powder that were 1 grams, 3 grams, 5 grams, 7 grams 9 grams, and control (without seed powder of $A$. muricata). The results of the research showed that the dose of 5 grams A. muricata seed powder showed highest mortality of $C$. maculatus by $94.0 \%$ at 8 days after infestation, reduced the amount of eggs which was oviposite by female of $C$. maculatus on mung bean seed $77.64 \%$. The emergence of the first generation of adult of C. maculatus was reduced by $74.67 \%$. The lowest of loss weight mung been seed amount $1.33 \%$.
\end{abstract}

Keywords: Annona muricata, Callosobruchus maculatus, Soursop Seed Powder, Mortality

\section{ABSTRAK}

Keefektifan Serbuk Biji Sirsak (Annona muricata L.) Terhadap Callosobruchus maculatus F. (Coleoptera: Bruchidae)

Callosobruchus maculatus F. (Coleoptera: Bruchidae) adalah salah satu hama utama yang menyebabkan kerusakan kacang hijau di tempat penyimpanan. Serangan C. maculatus ini menyebabkan menurunnya kualitas dan kuantitas biji kacang hijau. Penelitian ini dilakukan untuk mempelajari dosis efektif dari serbuk biji sirsak (Annona muricata) yang mengakibatkan mortalitas dan penekanan jumlah imago generasi pertama C. maculatus. Penelitian dilaksanakan di Laboratorium Hama Tanaman, Departemen Hama dan Penyakit Tumbuhan Fakultas Pertanian Universitas Padjadjaran Jatinangor dengan menggunakan metode Rancangan Acak Lengkap (RAL) dengan 6 perlakuan dan 5 ulangan. Perlakuan yang diuji terdiri dari 5 dosis serbuk biji A. muricata dengan dosis $1 \mathrm{~g}, 3 \mathrm{~g}, 5 \mathrm{~g}, 7 \mathrm{~g}$, dan $9 \mathrm{~g}$, ditambah dengan control (tanpa pemberian serbuk biji A. murucata). Hasil penelitian menunjukkan bahwa dosis $5 \mathrm{~g}$ serbuk biji A.muricata mengakibatkan mortalitas C.maculatus sebesar 94,0 \% pada 8 hari setelah infestasi, penekanan jumlah telur yang diletakkan C. maculatus pada benih kacang hijau sebesar $77,64 \%$. Penekanan munculnya jumlah imago generasi pertama pada benih kacang hijau sebesar 74,67\% serta kehilangan berat benih kacang hijau terendah sebesar 1,33\%

Kata Kunci : Annona muricata, Callosobruchus maculatus, Serbuk Biji Sirsak, Mortalitas

\section{PENDAHULUAN}

Di Indonesia, tanaman kacang hijau merupakan komoditi serealia ketiga yang banyak dibudidayakan setelah kedelai dan kacang tanah (Purwono \& Hartono, 2005). Callosobruchus maculatus F. (Coleoptera: Bruchidae) adalah salah satu hama utama di gudang penyimpanan yang dapat menyebabkan penurunan kualitas dan kuantitas biji kacang hijau selama pascapanen. Serangan hama ini dapat mengurangi bobot berkisar 50-70\% (Vimala \& Pushpamma, 1983). Perkembangbiakan C. maculatus. cukup cepat, dalam waktu sembilan hari seekor imago betina mampu meletakkan telur sekitar 128 butir (Talekar, 1987).

Penggunaan pestisida kimia sintesis dalam pengendalian $C$. maculatus. di gudang penyimpanan yang umum dilakukan yaitu dengan cara fumigasi. Namun, fumigasi yang berlebih dan terus menerus dapat menimbulkan dampak negatif, diantaranya resistensi, resurgensi, serta dapat meninggalkan residu pestisida pada produk hasil pertanian yang bisa berbahaya apabila dikonsumsi manusia (Elda, 2009).

Adanya dampak negatif dari pengendalian menggunakan insektisida sintetik, maka diperlukan alternatif pengendalian yang ramah terhadap manusia dan lingkungan serta efektif bagi serangga sasaran. Salah satu cara pengendalian tersebut yaitu dengan menggunakan bahan alami yang berasal dari tumbuhan atau tanaman sebagai insektisida nabati (Mardiningsih \& Kardinan, 1995).

Menurut Gainge \& Ahmed (1988) lebih dari 100 spesies tumbuhan mengandung bahan insektisida. Adanya keanekaragaman tumbuhan di Indonesia memiliki peluang yang tinggi untuk memperoleh sumber insektisida nabati yang potensial. Namun, sampai saat ini pemanfaatannya belum maksimal. 
Insektisida nabati memiliki kelebihan tertentu yang tidak dimiliki oleh insektisida sintetik, salah satunya adalah memiliki sifat yang tidak stabil sehingga memungkinkan terdegadasi secara alami (Kardinan, 2006). Hal ini membuka peluang bagi pemanfaatan bahan alami tumbuhan untuk mengendalikan serangga hama. Beberapa contoh tanaman yang telah dimanfaatkan sebagai pestisida hayati antara lain mimba (Azadirachta indica A. Juss), tembakau (Nicotiana tabacum L.), serei wangi (Andropogon nardus L.), pyrethrum (Chrysanthemum cinerariaefolim VIS), bakung (Crinum asiaticum L,), sirih (Piper betle L.), mindi (Melia azedarach L.), cengkeh (Syzygium aromaticum L.), dan sirsak (Annona muricata L.) (Kardinan, 2005).

Bagian tanaman yang digunakan untuk penelitian ini adalah biji sirsak yang mengandung senyawa kimia Annonain yang bersifat racun kontak dan racun perut. Biji sirsak dilaporkan bermanfaat sebagai insektisida yang bersifat repellent (penolak) dan antifeedant. (Kardinan, 2005).

\section{BAHAN DAN METODE}

Percobaan dilaksanakan di Laboratorium Hama Tanaman, Departemen Hama dan Penyakit Tumbuhan, Fakultas Pertanian, Universitas Padjadjaran, Jatinangor dengan ketinggian 700 meter di atas permukaan laut dan suhu rata-rata $27{ }^{\circ} \mathrm{C}$ serta kelembaban rata-rata $70 \%$. Imago $C$. maculatus asal BIOTROP (Tropical Biology) Bogor, benih kacang hijau, biji sirsak yang di dapat dari daerah Garut (Jawa Barat). Metode penelitian yang digunakan adalah metode eksperimen dengan Rancangan Acak
Lengkap (RAL) yang terdiri dari 6 perlakuan dan masing-masing perlakuan diulang 5 kali. Perlakuan yang diuji terdiri dari sebuk biji sirsak : kacang hijau (g/g) : A (1g/100 g), B (3 g/100g), C (5 g/100g), D (7 $\mathrm{g} / 100 \mathrm{~g}), \mathrm{E}(9 \mathrm{~g} / 100 \mathrm{~g})$, dan F (control $100 \mathrm{~g}$ kacang hijau).

Data mortalitas, jimlah telur yang diletakkan, jumlah generasi pertama yang muncul, dan kehilangan bobot kacang hijau dianalisis secara statistika dengan menggunakan progam SPSS versi (16.0). Perbedaan antar perlakuan diuji dengan menggunakan Uji Jarak Berganda Duncan pada taraf nyata $5 \%$.

\section{HASIL DAN PEMBAHASAN}

\section{Mortalitas Imago Callosobruchus maculatus}

Mortalitas imago $C$. maculatus pada benih kacang hijau yang diberi perlakuan serbuk biji sirsak pada semua taraf dosis menyebabkan kematian imago C. maculatus. Kematian C. maculatus pada setiap perlakuan serbuk biji sirsak menunjukkan peningkatan seiring dengan bertambahnya dosis serbuk yang diuji (Tabel 1).

Pada pengamatan 2 hari setelah infestasi (HIS) mulai terlihat adanya peningkatan mortalitas pada perlakuan serbuk biji sirsak. Perlakuan serbuk biji sirsak dengan dosis $9 \mathrm{~g}$ menunjukkan pengaruh paling besar apabila dibandingkan dengan perlakuan dosis yang lainnya dan menunjukkan bahwa semakin tinggi dosis maka semakin tinggi pula mortalitas yang diakibatkannya.

Tabel 1. Pengaruh Serbuk Biji Sirsak terhadap Mortalitas Imago C. maculatus.

\begin{tabular}{llllc}
\hline \multirow{2}{*}{ Perlakuan } & \multicolumn{3}{l}{ Mortalitas (\%) } \\
\cline { 2 - 5 } & $2 \mathrm{HSI}$ & $4 \mathrm{HSI}$ & $6 \mathrm{HSI}$ & $8 \mathrm{HSI}$ \\
\hline Serbuk Biji Sirsak 1 g & $28 \mathrm{~b}$ & $42 \mathrm{~b}$ & $52 \mathrm{~b}$ & $78 \mathrm{~b}$ \\
Serbuk Biji Sirsak 3 g & $36 \mathrm{~b}$ & $48 \mathrm{bc}$ & $56 \mathrm{bc}$ & $88 \mathrm{c}$ \\
Serbuk Biji Sirsak 5 g & $46 \mathrm{c}$ & $56 \mathrm{c}$ & $66 \mathrm{~cd}$ & $94 \mathrm{~cd}$ \\
Serbuk Biji Sirsak 7 g & $56 \mathrm{~d}$ & $66 \mathrm{~d}$ & $74 \mathrm{~d}$ & $98 \mathrm{de}$ \\
Serbuk Biji Sirsak 9 g & $62 \mathrm{~d}$ & $72 \mathrm{~d}$ & $92 \mathrm{e}$ & $100 \mathrm{e}$ \\
Kontrol & $0 \mathrm{a}$ & $0 \mathrm{a}$ & $0 \mathrm{a}$ & $0 \mathrm{a}$
\end{tabular}

Keterangan : Nilai rata-rata yang diikuti huruf yang sama pada kolom yang sama menunjukkan tidak berbeda nyata menurut Uji jarak Berganda Ducan pada taraf $5 \%$.

Mortalitas $C$. maculatus pada 8 HSI tertinggi terjadi pada perlakuan biji sirsak $A$. muricata dengan dosis $9 \mathrm{~g}$ yaitu sebesar $100 \%$, pada perlakuan ini menunjukkan hasil yang berbeda nyata dengan perlakuan yang lain. Hal ini disebabkan adanya senyawa kimia yang terkandung dalam serbuk biji sirsak yaitu senyawa Annonain yang bersifat racun kontak dan racun perut. Senyawa tersebut juga memiliki bioaktivitas bekerja sebagai repellent (penolak) dan antifeedant (Kardinan, 2001). Senyawa golongan Annonaceous acetogenin memiliki efek sebagai antifeedant terhadap serangga. Antifeedant adalah suatu substansi yang jika terpapar pada serangga akan menghentikan serangga tersebut untuk memenuhi kebutuhannya akan makanan (Coloma, 2002; Leatemia, 2004).

\section{Jumlah Telur}

Hasil penelitian menunjukkan bahwa penggunaan serbuk biji sirsak dapat menekan jumlah telur yang diletakkan $C$. maculatus pada benih kacang hijau (Tabel 2). Jumlah telur terendah terjadi pada 
perlakuan serbuk biji sirsak dengan dosis $9 \mathrm{~g}$ yaitu sebanyak 256 butir. Sedangkan jumlah telur tertinggi terjadi pada perlakuan kontrol yaitu sebanyak 2104 butir. Penekanan peletakan telur diduga karena banyaknya imago yang mati akibat pemberian perlakuan sehingga kopulasi terganggu atau bakhan karena tidak sempat berkopulasi sama sekali.

Tabel 2. Pengaruh Serbuk Biji Sirsak terhadap Jumlah Telur yang Diletakkan C. maculates pada Kacang Hijau

\begin{tabular}{lll}
\hline Perlakuan & $\begin{array}{l}\text { Rata-rata Jumlah Telur } \\
\text { (butir) }\end{array}$ & Penekanan (\%) \\
\hline Serbuk Biji Sirsak 1 g & $173,2 \mathrm{c}$ & $58,83 \mathrm{a}$ \\
Serbuk Biji Sirsak 3 g & $157,4 \mathrm{c}$ & $62,57 \mathrm{~b}$ \\
Serbuk Biji Sirsak 5 g & $94,2 \mathrm{~b}$ & $77,64 \mathrm{c}$ \\
Serbuk Biji Sirsak 7 g & $67,2 \mathrm{a}$ & $84,08 \mathrm{~d}$ \\
Serbuk Biji Sirsak 9 g & $51,2 \mathrm{a}$ & $87,89 \mathrm{e}$ \\
Kontrol & $420,8 \mathrm{e}$ & - \\
\hline
\end{tabular}

Keterangan: Nilai rata-rata yang diikuti huruf yang sama pada kolom yang sama menunjukkan tidak berbeda nyata menurut Uji Jarak Berganda Duncan pada taraf nyata 5\%.

Peletakan telur pada permukaan biji dipengaruhi oleh kekerasan kulit biji, permukaan biji dan adanya zat kimia tertentu pada permukaan biji (Nwanze et al., 1975 dalam Kardinan dan Wikardi, 1994), warna biji, ukuran, aroma, dan kadar air (Talekar \& Lin, 1981 dalam Supeno, 2005). Hal yang sama juga didukung oleh Dobie et al. (1984) bahwa preferensi peletakan telur dipengaruhi oleh sifat fisik permukaan biji. Biji yang licin, mengkilap dan berukuran besar sangat disukai untuk peletakan telur.

\section{Jumlah Imago Generasi Pertama}

Setelah 20 hari, terlihat adanya peningkatan populasi yang berbeda pada masing-masing perlakuan. Populasi imago hidup dari $C$. maculatus yang dihitung merupakan generasi pertama. Pengaruh perlakuan pada serbuk biji sirsak terhadap munculnya imago pertama ditunjukan dengan berkurangnya jumlah imago pertama yang muncul seiring dengan meningkatnya konsentrasi yang diuji (Tabel_3).
Pada perlakuan serbuk biji sirsak dengan dosis 9 gam memberikan pengaruh penekanan kemunculan imago generasi pertama sebesar $89,42 \%$ yang lebih besar apabila dibandingkan dengan perlakuan lainnya. Perlakuan serbuk biji sirsak $A$. muricata dengan dosis $1 \mathrm{~g}$ memberikan pengaruh paling rendah dibandingkan dengan perlakuan lain yaitu sebesar $54,45 \%$.

Minimnya jumlah imago yang muncul diduga disebabkan adanya pengaruh dari serbuk biji sirsak yang mengandung racun dan menempel pada permukaan benih, sehingga dapat mengganggu aktivitas larva, nyebabkan larva keracunan dan kemudian mati. Keadaan yang kurang menguntungkan akibat adanya senyawa kimia akan mempengaruhi aktivitas larva selama perkembangan dan pertumbuhan (Horber, 1978 dalam Nuryati, 2008).

Tabel 3. Pengaruh serbuk biji sirsak Terhadap Jumlah Imago Generasi Pertama C. maculatus.

\begin{tabular}{lcl}
\hline Perlakuan & $\begin{array}{l}\text { Rata-rata Imago } \\
\text { Generasi Pertama (ekor) }\end{array}$ & $\begin{array}{l}\text { Penurunan } \\
\text { Populasi (\%) }\end{array}$ \\
\hline Serbuk Biji Sirsak 1 g & $114,0 \mathrm{c}$ & $54,45 \mathrm{a}$ \\
Serbuk Biji Sirsak 3 g & $90,0 \mathrm{c}$ & $64,03 \mathrm{~b}$ \\
Serbuk Biji Sirsak 5 g & $63,8 \mathrm{~b}$ & $74,67 \mathrm{c}$ \\
Serbuk Biji Sirsak 7 g & $35,2 \mathrm{a}$ & $85,96 \mathrm{~d}$ \\
Serbuk Biji Sirsak 9 g & $26,6 \mathrm{a}$ & $89,42 \mathrm{~d}$ \\
Kontrol & $251,6 \mathrm{e}$ & - \\
\hline
\end{tabular}

Keterangan: Nilai rata-rata yang diikuti huruf yang sama pada kolom yang sama menunjukkan berbeda nyata menurut Uji Jarak Berganda Duncan pada taraf 5\%.

\section{Kehilangan Berat Benih Kacang Hijau}

Hasil pengamatan menunjukkan bahwa kehilangan berat benih kacang hijau menurun seiring dengan bertambahnya dosis perlakuan serbuk biji sirsak A. muricata. Kehilangan berat benih kacang hijau tertinggi terjadi pada kontrol dengan rata-rata kehilangan berat benih kacang hijau sebesar 5,90\%. Kehilangan berat terendah terjadi pada perlakuan 
serbuk biji sirsak dengan dosis $9 \mathrm{~g}$ dengan rata-rata kehilangan berat benih kacang hijau sebesar $0,56 \%$ berdasarkan Uji Jarak Berganda Duncan pada taraf 5 $\%$ (Tabel 4).

Tabel 4. Pengaruh Serbuk Biji Sirsak Terhadap Kehilangan Berat Benih Kacang Hijau

\begin{tabular}{lc}
\hline Perlakuan & Kehilangan Berat Benih (\%) \\
\hline Serbuk Biji Sirsak 1 g & $3,29 \mathrm{~d}$ \\
Serbuk Biji Sirsak 3 g & $2,74 \mathrm{c}$ \\
Serbuk Biji Sirsak 5 g & $1,33 \mathrm{~b}$ \\
Serbuk Biji Sirsak 7 g & $0,71 \mathrm{a}$ \\
Serbuk Biji Sirsak 9 g & $0,56 \mathrm{a}$ \\
Kontrol & $5,90 \mathrm{e}$ \\
\hline
\end{tabular}

Keterangan: Nilai rata-rata yang diikuti huruf yang sama pada kolom yang sama menunjukkan berbeda nyata menurut Uji Jarak Berganda Duncan pada taraf 5\%.

Kehilangan berat benih dapat disebabkan karena adanya sebagian benih yang dimakan oleh larva sehingga kualitas benih menurun (Talekar, 1987). Benih menjadi berlubang, keropos atau hancurnya menjadi butiran kecil atau tepung (Sutopo, 1998). Rendahnya kehilangan berat benih kacang hijau disebabkan oleh sedikitnya larva yang berkembang.

\section{KESIMPULAN}

Perlakuan serbuk biji sirsak A. muricata dengan dosis $5 \mathrm{~g}$ per $100 \mathrm{~g}$ kacang hijau menyebabkan mortalitas $C$. maculatus dengan ratarata sebesar $94 \%$ pada 8 hari setelah infestasi dengan menyebabkan penekanan jumlah telur sebesar 77,64 $\%$, menekan munculnya jumlah imago generasi pertama sebesar 74,67\%, dan kehilangan berat benih terendah sebesar $1,33 \%$. Serbuk biji sirsak dengan dosis $5 \mathrm{~g}$ dapat digunakan sebagai alternatif pengendalian $C$. maculatus pada benih kacang hijau di tempat penyimpanan.

\section{DAFTAR PUSTAKA}

Coloma \& A. Gonzales. 2002. Selective Action of Acetogenin Mitochondrial complex I Inhibitor.

Dobie, P., C. P. Haines, R. J. Hodges, \& P. F. Prevett. 1984. Insect and Arachnids of Tropical Stored Product: Their Biology and Identification (A Training Manual). Tropical Products Institute. Slough. United Kingdom.

Elda. 2009. Pemanfaatan Senyawa Kimia Alami Sebagai Alternatif Pengendalian Hama Tanaman. http://www.chem-is-try.org. Diakses 25 April 2013.

Gainge, M. \& S. Ahmed. 1988. Handbook of Plants with Pest Control Properties. Jhon Wiley and Sons. New York.

Kardinan, A \& E. A. Wikardi. 1994. Pengaruh Abu Limbah Serai Dapur dan Tepung Bawang Putih Terhadap Hama Gudang Callosobruchus analis F. (Coleoptera:
Bruchidae). Buliten Penelitian Tanaman Rempah dan Obat. Vol.IX :1.

Kardinan, A. 2005. Pestisida Nabati, Ramuan dan Aplikasi. Penebar Swadaya. Jakarta.

Kardinan, A., 2001. Pestisida Nabati Ramuan dan Aplikasinya. Penebar Swadaya, Jakarta.

Kardinan, A. 2006. Mimba (Azadirachta indica) Bisa Merubah Perilaku Hama. Balai Penelitian Tanaman Rempah dan Obat. Bogor. 4p

Leatemia, J.A. 2004. Insecticidal Activity of Crude Seed Extract of Annona spp., Lansium domesticum and Sandoricum Koetjape againts Lepidopteran_Larvae. http://www.ncbi.nlm. nih.gov/entrez/query.fcgi? $\mathrm{cmd}=$ Retrieve $\& \mathrm{db}=\mathrm{p}$ ubmed\&dopt=Abstract\&list_uids=1298795\&it ool=iconabstr\&query_hl=1 diakses tanggal 20 Agustus 2013)

Mardiningsih, T.L. \& A. Kardinan. 1995. Effect of Lemon grass and Citronella Oils from Leaves and Stalks. Bogor. Journal of Spice Medicinal Crops. 3 (2): 41-44.

Nuryati. 2008. Pengaruh Serbuk Daun Serai (Andropogon citrates STAPF) (Poales: Poaceae) Terhadap Mortalitas dan Populasi Generasi Pertama Sitophilus zeamais MOTSCH. (Coleoptera: Curculionidae) Pada Benih Jagung. Skrpsi. Jurusan Hama dan Penyakit Tumbuhan, Fakultas Pertanian, Universitas Padjadjaran. Bandung. 57p.

Purwono \& R. Hartono. 2005. Kacang Hijau. Niaga Swadaya, Bogor.

Sutopo, L. 1998. Teknologi Benih. Fakultas Pertanian Universitas Brawijaya. PT. Raja Gafindo persada. Jakarta.

Talekar, N. S. 1987a. Biology, damage and control of bruchid pests of mungbean in Proceedings of The Second International Symposium. Bangkok, Thailand.

Talekar, N. S. 1987b. Insect Pests of Mubgbean and Their Control. Asian Vegetable Research dan Development Center. Taiwan. 
Vimala, V. \& P. Pushpamma. 1983. Storage quality of pulses stored in three ago climatic regions of Andhra Pradesh. Bulletin of Gain Technology. 21: $157-158$ 